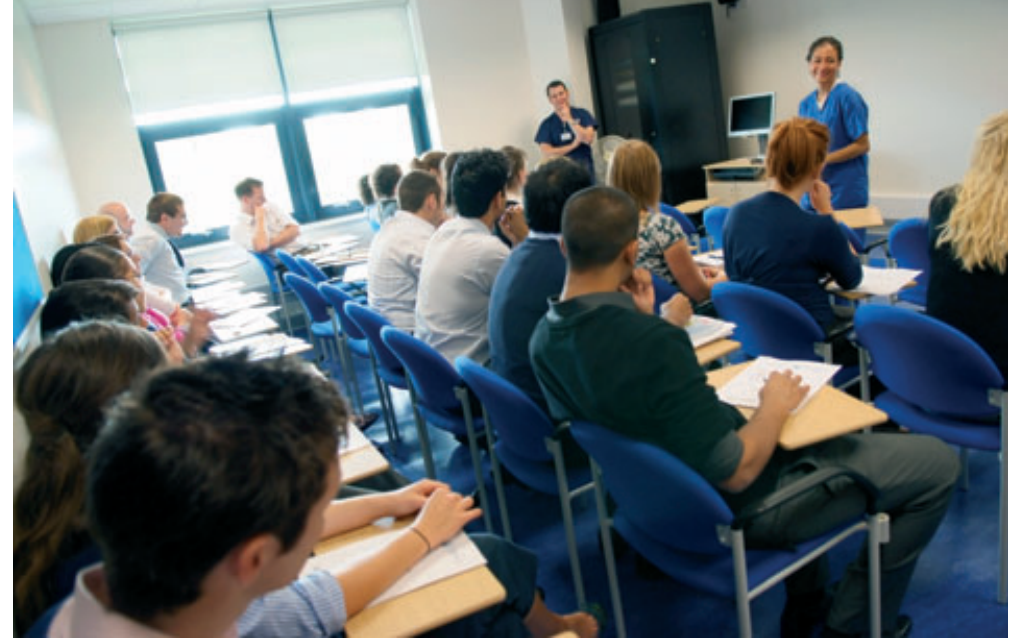

\title{
Evaluation
}

\section{Using evaluation research to improve medical education}

Mohsen Tavakol, Medical Education Unit, The University of Nottingham, UK Larry D. Gruppen, Department of Medical Education, University of Michigan Medical School, Ann Arbor, Michigan, USA

Sima Torabi, The Nottingham Emmanuel School, Nottingham, UK

The use of evaluation research

findings helps medical educators to make informed decisions regarding a programme

\section{SUMMARY}

Background: Evaluation research is a form of applied research that scrutinises how well a particular programme, practice, procedure or policy is operating. Evaluation researchers use both quantitative and qualitative research data to construct a collective picture of the programme under evaluation. Context: Medical educators need to provide information about a particular programme using the methods of evaluation research in order to make a decision on the potential adoption, improvements and refinements of the pro-

gramme. Improving curricula and pedagogical methods using these methods may enhance health care education.

Innovation: We provide an overview of the methods of evaluation research in the context of medical education. We discuss the application, general methodology, methods of collecting data and analysis for each type of evaluation research.

Implications: The methods of evaluation research described in this article enable medical educators to gain a comprehensive understanding of evaluation research in the context of medical education. The use of evaluation research findings helps medical educators to make informed decisions regarding a programme and any future actions related to it. 


\section{INTRODUCTION}

U nless an agency does not take its avowed purposes seriously', wrote Stephansome 65 years ago, "it should be interested to know whether past activity actually produced the results that were expected. It will also be concerned to know how reasonable its expectations of future results may be'. ${ }^{1}$ Since that time, there has been increased interest in research that is designed to measure the performance of a programme, practice, procedure or policy. Today's medical educators are faced with a variety of challenges from patients, society, doctors and students. ${ }^{2}$ Such challenges persuade medical educators to change curricula and pedagogical strategies to enhance the quality of patient care, an outcome at the top of Kirkpatrick's hierarchy of evaluation outcomes (Figure 1). ${ }^{3}$ To achieve this, it is necessary for medical educators to develop evaluation research as a routine tool for making changes and improvements based on experimental data. For the purpose of this paper, evaluation here refers to activities that are composed of both description and judgment of a programme, practice, procedure or policy to improve local medical education development. This is in contrast to the term 'assessment', which is used to describe the measurement of individual learner performance.

Evaluation research is applied research that examines how well a specific programme, practice, procedure or policy is working. ${ }^{4}$ It is a systematic approach to collecting reliable and valid data about the outcomes or effects of a programme through the provision of empirically driven data.

Evaluation researchers typically seek to study the application of existing knowledge rather than make contributions to new knowledge. ${ }^{5}$ The research objective in evaluation research is

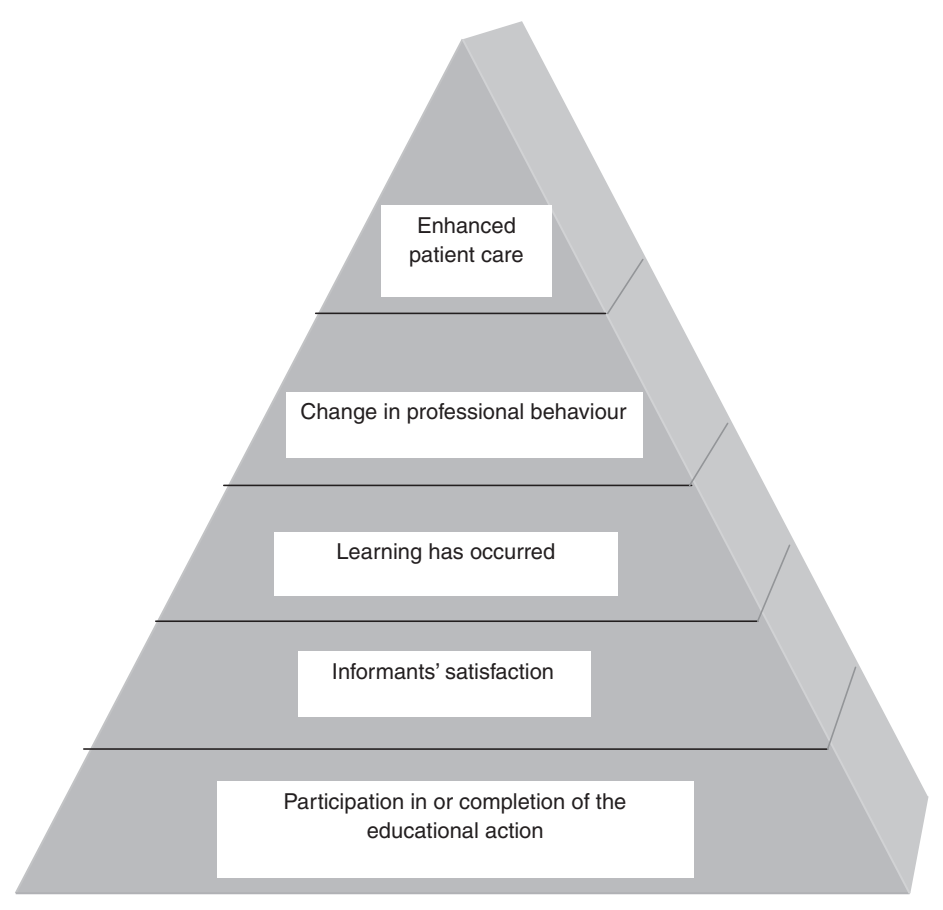

Evaluation

research is

applied

research that

examines how

well a specific

programme,

practice,

procedure or

policy is

working 'utilitarian', and the purpose of the study is to answer the practical questions of the people who will make the decisions regarding programmes. ${ }^{6}$

It is noteworthy that evaluation research uses both quantitative and qualitative inquiry to evaluate a programme, procedure, practice or policy. The data collection methods include interviews, group interviews, journaling, site visits, field notes, documentary evidence and questionnaires. Such tools provide a descriptive and inferential means to determine the effect of the outcomes of a programme, to portray the worth of an action and to revise a specific programme. However, evaluation research can be threatening for people who are implementing a programme. People feel uncomfortable when their work is being evaluated, and may feel that their jobs or reputation are at stake. ${ }^{4}$ For this reason, evaluation researchers need to have not only methodological skills, but also diplomacy and interpersonal communication skills. ${ }^{4}$

\section{EVALUATION VERSUS RESEARCH}

Both evaluation and research in medical education seek evidence for developing practice, setting policy, planning standards for education and making educational decisions. Fain said it best, 'Evaluation and research are closely related and should be synergistic'. ${ }^{7}$ However, it is important to differentiate between evaluation and research. Evaluation provides an overview of medical education issues; research is a biopsy of medical education practice. ${ }^{8}$ The major differences between evaluation and research have been presented in different dichotomies: evaluation particularises, research generalises; ${ }^{9}$ evaluation makes decisions for programmes, research makes a systematic inquiry to validate old knowledge and generate new knowledge. ${ }^{10}$

Evaluators tend to focus on context, localised results, politics, the audience(s) and the decision-making process. Researchers, on the other hand, focus more on 
Several models

have been

developed to

guide the

evaluation of a

given

programme
Table 1. Distinguishing between the types of evaluation research

\begin{tabular}{|c|c|c|}
\hline & $\begin{array}{l}\text { Process } \\
\text { analysis (PA) }\end{array}$ & $\begin{array}{l}\text { Outcome } \\
\text { analysis }(O A)\end{array}$ \\
\hline Application & $\begin{array}{l}\text { Answers questions } \\
\text { regarding the } \\
\text { functioning of a } \\
\text { programme. }\end{array}$ & $\begin{array}{l}\text { Answers whether a } \\
\text { programme is } \\
\text { fulfilling its goals. } \\
\text { Used to decide } \\
\text { whether to } \\
\text { discard, replace, } \\
\text { modify, continue } \\
\text { or replicate the } \\
\text { programme. }\end{array}$ \\
\hline
\end{tabular}

Impact

analysis (IA)

Cost-benefit

analysis (CBA)

Cost-

effectiveness

analysis (CEA)

Identifies the

net impact of

an intervention

and describes

relative

efficiency.

\section{Identifies}

A formative

analysis.

the function of a

programme, the A descriptive

evaluation is analysis.

called formative Spells out

evaluation.

effectiveness.

A descriptive Typically analysis.

descriptive to

evaluate a

programme.

Methodology Uses both qualitative and quantitative

approaches.

A combination of studies.

the two might be

best to achieve

confirmation and

completeness of

findings.

$\begin{array}{ll}\text { Methods of } & \text { Uses a range of } \\ \text { collecting } & \text { methods of data } \\ \text { data } & \text { collection, such } \\ & \text { as questionnaire } \\ & \text { surveys, depth } \\ & \text { interviews, group } \\ & \text { interviews and } \\ & \text { observations of } \\ & \text { the programme. }\end{array}$

Randomised controlled trials.

Pre-post design.

Epidemiological

Uses quantitative
approaches, such
as experimental
designs
(randomised
controlled trials)
and quasi-
experimental
design
(pre-test/post-test
experimental
design).

A summative analysis.

Weighs the

positive

elements

against the

negative, and

then chooses

the most

profitable

option. Uses

retrospective

and prospective

methods. whether the

benefits of a

programme

outweigh the

cost. Used to

decide whether

to continue or

discontinue a

programme.

Estimate the costs and educational effects of an intervention. This helps to compare the costs with the associated costs from other interventions to select the best educational intervention.

\section{A summative} analysis Preferred analytical approach over CBA.

\section{Retrospective and prospective methods.}

See CEA data, such as
Data collection is typically grounded in economic evaluation and experimental randomised trials. In the absence of dedicated trials, the researcher draws on the existing literature. More detailed information regarding collecting data can be found in the work of Muennig and Robinson. ${ }^{16,17}$ 
methodological rigour, replication, generalisable results and theory building. ${ }^{10}$

\section{EVALUATION RESEARCH MODELS}

Several models have been developed to guide the evaluation of a given programme, each emphasising a particular aspect of the programme or outcomes. Table 1 shows the types of evaluation research models that use both qualitative and quantitative inquiry approaches to answer evaluation questions. The main evaluation research models are summarised below.

\section{Process or implementation analysis}

Process analysis is the most frequent form of programme evaluation. Process (or implementation) analysis, as stated by Scheirer,' verifies what the programme is and whether or not it is delivered as intended to the targeted recipients'. ${ }^{11}$ It does not analyse the effects of the programme on those recipients. ${ }^{12}$ Process or implementation analysis considers inputs, activities, processes and structures. Process analysis informs education decision makers what is happening in the programme, how the programme has developed, and how and why programmes deviate from original plans and expectations. ${ }^{13}$ A process or implementation analysis may be a formative evaluation if the aim of analysis is to improve a new or ongoing programme. Sometimes the purpose of the process analysis is mainly to spell out a programme carefully so that decision makers can better understand why the programme was or was not effective in achieving its objectives. ${ }^{4}$

\section{Outcome analysis}

Outcome analysis evaluates a programme in terms of its effect upon recipients, but does not focus significantly on the reasons why the outcome occurred. The

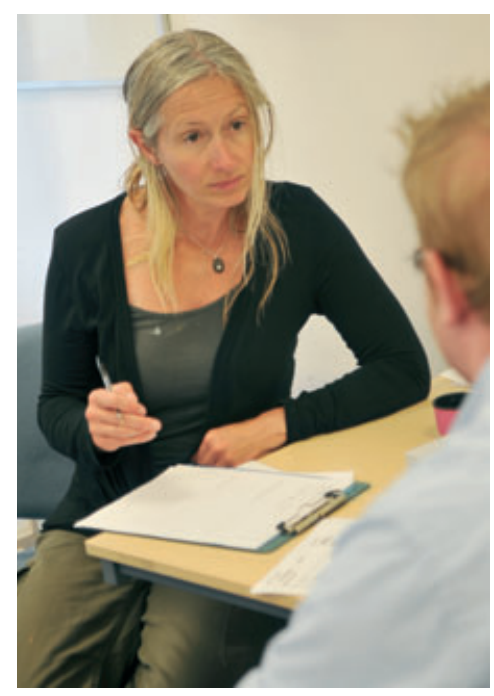

intent of such analysis is to help programme directors or policy makers decide whether the programme or policy should be discarded, replaced, modified, continued or replicated. ${ }^{4}$ Outcome analysis simply documents the extent to which programme goals are attained.

\section{Impact analysis}

Impact analysis involves producing an estimate of the net effect of an intervention; that is, the impacts that can be attributed exclusively to the intervention rather than to the effects of other factors (e.g. standard education). Impact analyses often involve subgroup analyses to identify the types of participants for whom an intervention is most effective. For example, the researcher might compare problem-based learning (PBL) impacts for girls and boys, for school leavers, graduate entry medicine and so on.

\section{Economic analysis}

An economic analysis evaluates the relationship between the cost of a programme and its effects. Decision makers' concerns include whether a programme induces sufficient benefits in relation to its costs, and whether other interventions or delivery systems can generate the same benefit at a lower cost. ${ }^{12}$ There is a large and growing literature on educational cost studies in both developed and developing countries that show how cost analysis can improve policy making and evaluation in education. ${ }^{14}$ Medical educators should recognise the importance and usefulness of cost analysis in educational policy making and evaluation by asking questions such as: are the economic benefits of the programme more important than the economic costs; is it worth conducting at all?

Cost-benefit analysis and costeffectiveness analysis are the two most common economic analyses. Cost-benefit analysis attempts to identify all the costs and benefits arising from a programme to provide an overall evaluation of its impact. However, it is not easy to gauge the benefits of educational services, nor the value of human life in monetary terms. ${ }^{15}$ However, if fiscal costs are part of the evaluation research question, a cost-benefit analysis is the best method for evaluating costs and benefits. Cost-effectiveness analysis shows the effects of education (such as student learning) relative to the costs incurred in accomplishing the educational outcomes. The costs for similar intervention methods are then compared in order to select the best (most cost-effective) educational intervention. Applications of this method have been made to lecturer selection, visual learning-based education, choice of a curriculum, distributed interactive learning environment and the use of educational strategies.

\section{CONCLUSION}

One of the responsibilities of medical educators is to determine how well a complex programme operates in medical education practice. This awareness may persuade medical educators to
If fiscal costs are part of the evaluation

research

question, a

cost-benefit

analysis is the

best method for evaluating costs and benefits 
Medical develop curricula and pedagogical educators need practice to enhance the quality of to become patient care, an outcome at the familiar with top of Kirkpatrick's pyramid in medical education. Medical methods of evaluation research

educators need to become familiar with methods of evaluation research as part of everyday work life. Evaluation research is applied research that involves learning how well a specific programme, practice, procedure or policy is working. A variety of methods of evaluation research are compared. There is clearly a strong demand for such evaluation and a need for knowledge-based economic evaluation.

\section{REFERENCES}

1. Stephan F. Training for research in social welfare Journal of Educational Sociology 1936;9:284-290.

2. Dent J, Harden M. New horizons in medical education. In: Dent $\mathrm{J}$, Harden R, eds. A practical guide for medical teachers. London: Elsevier Limited; 2005.
3. Wall D. Evaluation: improving practice, influencing policy. Edinburgh: ASME; 2007.

4. Polit D, Beck C. Nursing research: Generating and assessing evidence for nursing practice. New York: Lippincott Williams \& Wilkins; 2007.

5. Luker K. An overview of evaluation research in nursing. Journal of advanced nursing 1981;6:87-93.

6. Rossi P, Lipsey M, Freeman H. Evaluation: A Systematic Approach. London: Sage Publications; 2003.

7. Fain J. Is there a difference between evaluation and research? The Diabetes Educator 2005;31:154-155.

8. Woody M. An evaluator's perspective. Nursing Research 1980;29:74-77.

9. Morrison J. Evaluation. BMJ 2003;326:385-387.

10. Holzemer W. Research and evaluation: an overview. Quality review bulletin 1980;3:31-34.

11. Scheirer M. Designing and using process evaluation. In: Wholey $\mathrm{J}$, Hatry H, Newcomer K, eds. Handbook of practical programme evaluation. San Francisco: Jossey-Bass;1994; pp. 40-68.
12. Rossi P, Lipsey M, Freeman $\mathrm{H}$. Evaluation: A Systematic Approach Thousand Oaks, CA: Sage Publications; 2004.

13. Patton M. Qualitative research and evaluation methods. London: Sage Publication; 2002.

14. Chang W, Henry B. Methodological principles of cost analysis in the nursing, medical and health services literature, 1990-1996. Nursing Research 1999;48:94-104.

15. Russell LB, Gold MR, Siegel JE, Daniels N, Weinstein MC. The role of cost-effectiveness analysis in health and medicine. Panel on Cost-Effectiveness in Health and Medicine. JAMA 1996;276:1172-1177.

16. Muennig P. Cost effectiveness analysis in health: A practical approach. San Francisco: Jossey Bass; 2007.

17. Robinson R. Cost-effectiveness analysis. BMJ 1993;307:793-795.

Corresponding author's contact details: Dr Mohsen Tavakol, The University of Nottingham, Medical Education Unit, Nottingham, UK. E-mail:m_tavakol@yahoo.com, Mohsen.tavakol@nottingham.ac.uk

Funding: None.

Conflict of interest: None.

Ethical approval: This paper does not describe research on human subjects, therefore ethical approval was not necessary. 